\title{
Beyond exposure, sensitivity and adaptive capacity: a response based ecological framework to assess species climate change vulnerability
}

\author{
Lucas Fortini ${ }^{1,2^{*}}$ (D) and Olivia Schubert ${ }^{2,3}$
}

\begin{abstract}
As the impacts of global climate change on species are increasingly evident, there is a clear need to adapt conservation efforts worldwide. Species vulnerability assessments (VAs) are increasingly used to summarize all relevant information to determine a species' potential vulnerability to climate change and are frequently the first step in informing climate adaptation efforts. VAs commonly integrate multiple sources of information by utilizing a framework that distinguishes factors relevant to species exposure, sensitivity, and adaptive capacity. However, this framework was originally developed for human systems, and its use to evaluate species vulnerability has serious practical and theoretical limitations. By instead defining vulnerability as the degree to which a species is unable to exhibit any of the responses necessary for persistence under climate change (i.e., toleration of projected changes, migration to new climate-compatible areas, enduring in microrefugia, and evolutionary adaptation), we can bring VAs into the realm of ecological science without applying borrowed abstract concepts that have consistently challenged species-centric research and management. This response-based framework to assess species vulnerability to climate change allows better integration of relevant ecological data and past research, yielding results with much clearer implications for conservation and research prioritization.
\end{abstract}

Keywords: Species vulnerability assessments, Ecological responses, Toleration, Microrefugia, Migration, Evolutionary adaptation, Species distribution model

\section{Background}

The need for species climate change vulnerability assessments and their origins

Climate change is affecting ecosystems and organisms around the world. Increasing temperatures, altered precipitation patterns, higher sea-level, and shifted seasonal timing are just a few of the many variables impacting physiology, phenology, distribution, and composition among other characteristics of organisms [1] and ecological systems. VAs have been used to synthesize available information to determine the potential impacts of climate change on species of interest [2] providing an

\footnotetext{
* Correspondence: Ifortini@usgs.gov

${ }^{1}$ U.S. Geological Survey, Pacific Island Ecosystems Research Center, HI 96718 Hawaii National Park, USA

${ }^{2}$ Pacific Islands Climate Change Cooperative, HI 96813 Honolulu, USA

Full list of author information is available at the end of the article
}

opportunity to reanalyze, translate, and combine existing and new knowledge within the context of climate change.

VAs were developed within the social sciences to address issues within human systems such as risk management, political ecology, and natural disasters [3]. Key findings of these first VAs were used to inform policy, adaptation initiatives, community planners and individual households about climate-related risks and potential impacts [4-6]. The methods used to assess vulnerability have continually evolved, most notably after the IPCC's 2001 Assessment Report defined vulnerability as a function of exposure, sensitivity, and adaptive capacity (herein, the ESAC framework). Since then, researchers have attempted to construct tailored versions of climate change VAs using the ESAC framework in the agricultural, economic, and social disciplines [4, 7]. 
Nevertheless, the ESAC framework was not immediately adopted in climate change VAs for species and biological systems. Only after VAs became increasingly considered as a tool to initiate adaptation of conservation efforts [2] within the social realm did the number of ecological VAs using the ESAC framework increase, with examples including VAs for forest ecosystems, vegetation shifts, marine mammals, and native plant species [8-11]. With the increased use of the ESAC framework, it has now become the de facto approach to develop species VAs [12-14]. However, the framework was adopted and widely implemented without thorough discussion of whether it was an appropriate framework for biological systems.

While the ESAC framework of vulnerability is enticingly simple, it has received criticism for being based on abstract and unclear concepts [15]. Adaptive capacity and sensitivity are concepts that have been particularly challenging to characterize for species. Most species characteristics that confer high adaptive capacity are often traits that can be considered to also imply low sensitivity for a species (e.g., high genetic variability and dispersal capacity can both be viewed as either decreasing sensitivity or increasing adaptive capacity of a given species) [12, 16]. This fuzziness in definition results in the somewhat arbitrary classification of factors into overlapping categories used to summarize species overall vulnerability. Exposure, a measure of how much of a change in climate a species is likely to experience [2], is a component of the ESAC framework that is largely dependent on climate science and associated projections. As such, its assessment often requires ecologists to make probabilistic estimates of future climate scenarios [12], something that even the IPCC has not attempted. Along with exposure, these fuzzy concepts obscure the underlying response mechanisms that may make a species more or less vulnerable to climate change [15].

Particularly challenging is the evaluation of species adaptive capacity, a topic where little agreement exists [12]. As expected, species adaptive capacity often includes evolutionary adaptation as a subcomponent, but it also frequently includes other factors ranging from species traits to species management efforts that make comparison across assessments challenging. Some claim it is nearly impossible to empirically quantify adaptive capacity of individual species or communities [17]. Some studies disregard adaptive capacity altogether, focusing only on sensitivity and exposure [13], but this approach departs from an integrated, overall metric of potential climate change impacts on species. More recent attempts to include this factor in VAs $[18,19]$ generally highlight the challenging nature of applying such concepts to ecological systems [17].

\section{Main text}

An alternative approach: a response-based framework to assess species vulnerability to climate change

In contrast to the ESAC framework, a response-based framework provides a comprehensive framework of species vulnerability without requiring the consideration of abstract concepts that have posed significant challenges in the ecological realm. This response-based framework is instead based on an ecological foundation of numerous theoretical and field-based studies that relate species niche characteristics such as breadth and position to species responses to environmental change [20-23], and conversely, vulnerability $[24,25]$. Species climate change vulnerability can be characterized based on the full set of responses a species can exhibit to maintain or adapt its niche and thus persist under a shifting climate. Past work has described migration, tolerance, evolutionary adaptation, and extinction as the range of species responses to climate change [16, 26]. We expand on these species responses by considering an increasingly clear and distinct microrefugia response [27-29], and by dropping extinction as a response, as it is effectively the consequence of a lack of response. In this ecologicallybased formulation, species vulnerability is the degree to which a species is unable to exhibit any of the four responses necessary for persistence: 1) the migration response, in which a species follows (in a biogeographical sense) its moving climatic limits through dispersal and establishment in new areas where its niche becomes available [30-32]; 2) the microrefugia response, when the niche of a species persists in locations that retain suitable climate characteristics $[27,33-35]$ within a greater area that becomes unsuitable at the macro-climatic scale; 3) the toleration response, a situation when climate shifts fit within a species niche breadth [36-39]; 4) and the evolutionary adaptation response, when a species alters its niche to withstand changes in climate through natural selection [40, 41]. While there is no a priori reason for the existence of only the four response categories considered here, all documented species responses to climate shifts fit well within them, even in situations where more than one response has been observed $[16,42,43]$.

Using this framework, instead of relying on estimates of species sensitivity, exposure and adaptive capacity, an integrated measure of species' vulnerability can be calculated by estimating the likelihood or magnitude of such responses in the context of specific long-term (decadal) climate scenarios considered. This can be estimated by considering the multiple species characteristics that research has linked to each response (e.g., migration response as a function of dispersal distance, fertility, and dispersal barriers). 
When applied to species, the response-based vulnerability framework circumvents many limitations of the ESAC framework of vulnerability and offers several additional benefits (both described below). In Additional file 1 we compare a response-based versus an ESAC-based species vulnerability assessment for a highly vulnerable Hawaiian forest bird to illustrate differences between the two frameworks.

\section{Linking species traits and characteristics to vulnerability}

There is a wide variety of studies of species traits, characteristics, and responses to environmental change based on experimental and field-based studies, and modeling, [44-46] that are relevant to overall species vulnerability to climate change, but do not readily integrate with the predominant ESAC framework used to synthesize species information into overall vulnerability. Consequently, the need to integrate the science of climate change impacts on species is often recognized in the literature [26, 47], yet a working holistic framework is not available. In fact, studies document difficulties in bringing the ESAC components of the traditional VA framework into practice in terms of measurable units which are consistent and comparable among species [48, 49]. For instance, the 'migrate' response of a species can be estimated directly from the dispersal range of a species along with other relevant factors such as generation time and number of offspring. Similarly, the species "toleration" response may also be derived from estimates of a species' phenotypic or behavioral plasticity $[50,51]$. These and other species traits and characteristics can be quantified and integrated into the response-based framework, but are not so clearly useful in an ESAC-based vulnerability assessment (Fig. 1). This integration allows for an assessment of vulnerability based on an evaluation of all information relevant to a species' response to change.

\section{Integration of response studies into species vulnerability assessments}

Beyond research describing species traits and characteristics, numerous studies explore past and potential responses of species to climate shifts, such as documenting species range shifts over time [31], evolutionary adaptation [40] (both long- and short-term), as well as toleration of climate change [32]. Without a unifying framework, these response studies often attempt to reach conclusions about overall species vulnerabilities, but tend to link vulnerability only to the responses considered when in fact multiple species responses to climate change are possible. For instance, several studies have focused on the ability of species to migrate as the primary determinant of vulnerability [52, 53], failing to consider other responses (i.e., tolerate, persist in microrefugia, or evolutionary responses) influencing species vulnerability. The response-based framework can provide a valuable wider context to understand these studies' implications to species past behaviors and current vulnerability.

One particularly useful feature of a response-based species VA framework is the seamless inclusion of projected shifts in species distribution. VAs and species distribution models are commonly used to determine the

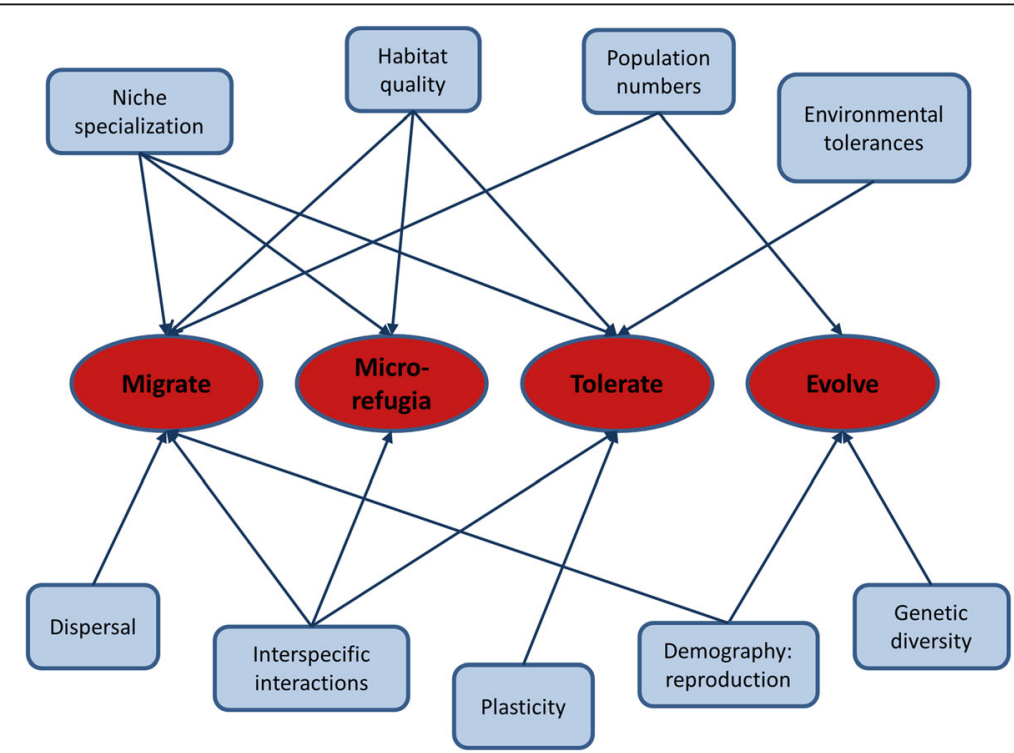

Fig. 1 Using a response-based framework, numerous species traits and characteristics can be related to the four responses underlying species vulnerability to climate change. Many other factors can be included, but the diagram includes an arbitrary number of traits and characteristics for illustrative purposes 
ecological impacts of climate change, although they have largely been used separately $[54,55]$. By defining vulnerability in terms of the four species responses proposed here, projected shifts in distribution can easily be related to migration, microrefugia, and toleration responses, and consequently into a response-based vulnerability framework. The Migration zone comprises areas beyond a species' current range and within a species' future range [56] that offer climatecompatible areas for potential species relocation. The Microrefugia zone consists of current climatecompatible areas that are projected to become macroclimatically incompatible by 2100 , but where the species might persist in small populations within micro-climatic refugia created by structurally complex habitat and related micro-climatic variability [27, 28, 57]. Lastly, the Toleration zone includes areas of overlap between current and future range where populations may persist due to changes being within the environmental range of conditions individuals of a species generally are expected to tolerate. These response zones downplay the importance of differences in individual niche requirements across the species range and possibly changing niche breadth due to an evolutionary response [58], but still yield a useful construct where geographical differentiation can be incorporated into species vulnerability assessments.

\section{Evaluation of complex ecological interactions}

Although descriptions of climate change vulnerability generally mention the interactions among climatic and non-climatic threats $[59,60]$, in practice, vulnerability assessments rarely evaluate these interactions. With a response-based species vulnerability model, the impact of current threats on a species' responses to climate can be directly explored by considering how they alter the probability of each of the possible species responses. Likewise, recent research has documented the importance of altered species interactions in shaping their responses to changing environments [61-63]. Such interactions can be summarized within a response-based framework by relating the likelihood or magnitude of species responses across interacting species. For instance, the migration response of a species may be partially dependent on the toleration response of potential competitor species currently occupying projected new ranges for the species, and vice versa. These complex species and threat interactions are at the core of ecology and are clearly relevant for any comprehensive assessment of species vulnerability, regardless of framework used. In contrast to the ESAC framework, a responsebased vulnerability framework provides a clearer way to consider and integrate these interactions given its ecological underpinnings.

\section{Research prioritization}

Since the ESAC framework of vulnerability is based on concepts outside of ecology, VA measures within that framework have limited utility in directing research necessary to fill gaps in ecological knowledge. For instance, it is not immediately clear how to prioritize research to improve estimates of species sensitivity to climate change, as sensitivity is an arbitrary and often ambiguous concept to measure. In contrast, considering vulnerability in terms of species responses immediately raises questions with clear implications for future ecological research, such as: What are the species characteristics and ecological context associated with an enhanced possibility of persistence within microrefugia? For species unlikely to tolerate projected changes, what is the relative importance of other responses? A response-based framework of vulnerability moves VAs into the realm of ecological science with clear implications for guiding research needs. Moreover, a response-based assessment is founded on responses that are directly observable and measurable, and thus can eventually be validated as opposed to a species VA based on the ESAC framework $[12,14]$. For instance, the measurement of actual range expansion in terms of elevation, latitude, or depth [31, $64,65]$; changing genotype frequencies in populations subject to change [66, 67]; and differences in growth, survival and reproduction among individuals within and outside potential microrefugia sites $[27,68,69]$ are some of the ways these responses can be eventually measured to validate earlier vulnerability assessments.

\section{Management relevance}

Although some have attempted to ascribe management recommendations to relative differences in $\mathrm{E}, \mathrm{S}$ and $\mathrm{AC}$ [13], these differences are not easily translatable into management actions for species (e.g., how should management differ among species with either high sensitivity or low adaptive capacity?) Focusing on species' responses instead allows for clearer management strategies. For example, a migration response to climate shifts can be supported through enhanced connectivity, augmented dispersal, and colonization assistance. Establishing and managing strategic reserves that are likely to retain suitable micro-climates may boost a microrefugia response (i.e., valley bottom and northern facing slopes). A toleration response can be assisted by reducing nonclimatic stressors in areas where species are expected to retain favorable climate space. An evolutionary response can also be managed by considering gene flow and diversity while maintaining minimum population sizes. Response-based assessments support concise and logical management options, which may be more readily interpreted and implemented than results describing differences in sensitivity or adaptive capacity. 


\section{Operationalizing climate change vulnerability based on species responses}

We have operationalized a simplified version of the response-based vulnerability framework in a recent assessment of the vulnerability of $>1000$ native Hawaiian plant species to climate change [70]. In that assessment, we used a Bayesian network model to estimate the relative likelihood of a species to exhibit the responses required to persist under a changing climate. For each of the responses considered, the likelihood of a species exhibiting a given response was based on a set of relevant landscape factors related to the amount, quality, and distribution of projected areas lost, gained, and maintained in climate-compatible areas between now and 2100. To integrate response likelihoods into a final vulnerability metric, we used a response-based species vulnerability index where a decreasing toleration response causes an increased importance of all other responses. In our findings we highlight multiple species for which management that boosts the chances for migration or microrefugia must be seriously considered, due to low prospects for a toleration response. Given the successful application of the simplified response-based vulnerability framework, we are expanding our analysis to include multiple species traits and characteristics pertinent to the species responses considered.

\section{Conclusions}

Abstract concepts have clearly impacted both the understanding and practice of biological conservation (e.g., biodiversity, resilience). Species vulnerability in itself is a useful concept as it integrates current and potential future impacts of climate change. However, most concepts currently utilized to characterize species vulnerability to climate change (e.g., sensitivity and adaptive capacity) do not bring added value to either the theoretical or management realms of ecology or conservation biology. Instead of developing increasingly complex approaches to make these ESAC concepts useable in ecological studies, we should consider whether characterizing vulnerability based on ecological concepts (environmental tolerances, microrefugia, species distribution shifts, evolutionary responses) is more defensible and informative.

We show that this simplified response-based framework has multiple advantages over the current ESAC framework for characterizing species vulnerability to climate change. The response-based framework provides an ecological definition of species vulnerability, which integrates individual species traits, incorporates projected species distribution shifts, and is based on variables that are observable and measurable. Identifying the ability of a species to exhibit any given response has clearer management implications, permits easier integration of climate change vulnerability with other non-climatic threats, and allows for the consideration of interspecific response interactions. Because of the clear ecological basis of the response-based framework, future research directions can more readily be identified and assessments more easily validated.

As ecologists, we are increasingly spending a substantial effort evaluating species vulnerabilities to help managers prepare for change. We should do this in a way that also advances our field. To that end, we are offering an alternative framework that hopefully can be improved upon and discussed in relationship to the current de facto framework that has been so broadly applied without question. Admittedly, implementing an ecological response-based framework will likely pose challenges. Fortunately these challenges will reflect the underlying gaps in ecological knowledge that a more comprehensive framework can help expose and gradually address.

\section{Additional file}

Additional file 1: Comparison of response-based vs ESAC-based species vulnerability assessments for a Hawaiian bird species, liwi (Drepanis coccinea) (DOCX $37 \mathrm{~kb})$

\section{Abbreviations}

ESAC: Exposure, sensitivity, adaptive capacity; IPCC: Intergovernmental Panel on Climate Change; VA: Vulnerability assessment

\section{Acknowledgments \\ We are grateful for the support of the U.S. Geological Survey Pacific Island Ecosystems Research Center and the Pacific Islands Climate Change Cooperative. We thank the comments and suggestions by Jeff Burgett, Christina Leopold, Whitney Peterson, Lauren Kaiser, and Julia Rowe.}

\section{Funding}

The U.S. Geological Survey Climate Change and Land Use Program provided funding for this research.

\section{Availability of data and materials}

Data sharing not applicable to this article as no datasets were generated or analyzed during the current study

\section{Author's contributions}

LF conceived concept and first draft of manuscript. LF and OS expanded and completed the manuscript. All authors read and approved the final manuscript.

\section{Author's information}

Lucas Fortini is a quantitative global change ecologist interested in how demographic and spatial dynamics of populations, species and communities shape opportunities for conservation and management of biodiversity under climate change. Olivia Schubert is a researcher and project manager who studies climate change in the Hawaiian Islands and has worked on projects involving carbon cycling, biofuel production, and paleoclimate reconstructions. Both are part of an interdisciplinary team at the Pacific Islands Climate Change Cooperative tasked with generating and sharing science to help managers and decision makers adapt conservation efforts to ongoing and projected climate shifts in the Pacific Islands.

Competing interests

The authors declare that they have no competing interests. 


\section{Consent for publication}

Not applicable

\section{Ethics approval and consent to participate}

Not applicable

\section{Publisher's Note}

Springer Nature remains neutral with regard to jurisdictional claims in published maps and institutional affiliations.

\section{Author details}

'U.S. Geological Survey, Pacific Island Ecosystems Research Center, HI 96718 Hawaii National Park, USA. ${ }^{2}$ Pacific Islands Climate Change Cooperative, HI 96813 Honolulu, USA. ${ }^{3}$ Hawai'i Cooperative Studies Unit, University of Hawai'i at Hilo, HI 96718 Hawaii National Park, USA

\section{Received: 17 May 2016 Accepted: 8 March 2017}

\section{Published online: 20 April 2017}

\section{References}

1. Walther G. Community and ecosystem responses to recent climate change. Philos Trans R Soc Biol Sci. 2010;365(1549):2019-24.

2. Glick P, Stein BA, Edelson NA. Scanning the conservation horizon: a guide to climate change vulnerability assessment. Washington: National Wildlife Federation; 2011. p. 142.

3. Fussel H-M, Klein R. Climate change vulnerability assessments: an evolution of conceptual thinking. Clim Change. 2006;75:301-29.

4. Ford JD, Smit B. A framework for assessing the vulnerability of communities in the Canadian artic to risks associated with climate change. Arctic. 2004; 57:389-400.

5. Metzger M, Leemans R, Schroter D. A multidisciplinary multi-scale framework for assessing vulnerabilities to global change. Int J Appl Earth Obs Geoinform. 2005;7:253-67.

6. de Chazal J, Quétier F, Lavorel S, Van Doorn A. Including multiple differing stakeholder values into vulnerability assessments of socio-ecological systems. Glob Environ Chang. 2008;18(3):508-20.

7. O'Brien K, Leichenko R, Kelkar U, Venema H, Aandahl G, Tompkins H, et al. Mapping vulnerability to multiple stressors: climate change and globalization in India. Glob Environ Change A. 2004;14(4):303-13.

8. Lindner M, Maroschek M, Netherer S, Kremer A, Barbati A, Garcia-Gonzalo J, et al. Climate change impacts, adaptive capacity, and vulnerability of European forest ecosystems. For Ecol Manage. 2010;259(4):698-709.

9. Fuentes $M$, Cinner J. Using expert opinion to prioritize impacts of climate change on sea turtles' nesting grounds. J Environ Manage. 2010;91(12): 2511-8.

10. Summers DM, Bryan BA, Crossman ND, Meyer WS. Species vulnerability to climate change: impacts on spatial conservation priorities and species representation. Glob Chang Biol. 2012;18(7):2335-48.

11. Gonzalez P, Neilson RP, Lenihan JM, Drapek RJ. Global patterns in the vulnerability of ecosystems to vegetation shifts due to climate change. Global Ecology and Biogeography.

12. Williams SE, Shoo LP, Isaac JL, Hoffmann AA, Langham G. Towards an integrated framework for assessing the vulnerability of species to climate change. PLoS Biol. 2008;6(12):e325.

13. Gardali T, Seavy NE, DiGaudio RT, Comrack LA. A climate change vulnerability assessment of California's at-risk birds. PLoS One. 2012;7(3): e29507.

14. Foden WB, Butchart SHM, Stuart SN, Vié J-C, Akçakaya HR, Angulo A, et al. Identifying the World's most climate change vulnerable species: a systematic trait-based assessment of all birds, amphibians and corals. PLoS One. 2013;8(6):e65427.

15. Hinkel J. Indicators of vulnerability and adaptive capacity: towards a clarification of the science-policy interface. Glob Environ Chang. 2011:21: $198-208$.

16. Dawson T, Jackson S, House J, Prentice I, Mace G. Beyond predictions: biodiversity conservation in a changing climate. Science. 2011:332:53-8.

17. Jones RN. The latest iteration of IPCC uncertainty guidance-an author perspective. Clim Change. 2011;108:733-43.

18. Beever EA, O'Leary J, Mengelt C, West J, Julius S, Green N, et al. Improving conservation outcomes with a New paradigm for understanding Species' fundamental and realized adaptive capacity. Conserv Lett. 2015;0:1-7.
19. Engle N. Adaptive capacity and its assessment. Glob Environ Chang. 2011; 21:647-56.

20. Thuiller W, Lavorel S, Araújo MB. Niche properties and geographical extent as predictors of species sensitivity to climate change. Glob Ecol Biogeogr. 2005;14(4):347-57.

21. Swihart RK, Lusk JJ, Duchamp JE, Rizkalla CE, Moore JE. The roles of landscape context, niche breadth, and range boundaries in predicting species responses to habitat alteration. Divers Distrib. 2006;12(3):277-87.

22. Öckinger E, Schweiger O, Crist TO, Debinski DM, Krauss J, Kuussaari M, et al. Life-history traits predict species responses to habitat area and isolation: a cross-continental synthesis. Ecol Lett. 2010;13(8):969-79.

23. Chase JM, Leibold MA. Ecological niches: linking classical and contemporary approaches. 1st ed. Chicago: University of Chicago Press; 2003. p. 216.

24. Broennimann O, Thuiller W, Hughes G, Midgley GF, Alkemade JMR, Guisan A. Do geographic distribution, niche property and life form explain plants vulnerability to global change? Glob Chang Biol. 2006;12(6):1079-93.

25. Slatyer RA, Hirst M, Sexton JP, Kleijn D. Niche breadth predicts geographical range size: a general ecological pattern. Ecol Lett. 2013;16(8):1104-14.

26. O'Connor M, Selig ER, Pinksy M, Altermatt F. Toward a conceptual synthesis for climate change responses. Glob Ecol Biogeogr. 2012;21:693-703.

27. Dobrowski SZ. A climatic basis for microrefugia: the influence of terrain on climate. Glob Chang Biol. 2011;17:1022-35.

28. Ashcroft MB, Gollan JR, Warton DI, Ramp D. A novel approach to quantify and locate potential microrefugia using topoclimate, climate stability, and isolation from the matrix. Glob Chang Biol. 2012;18:1866-79.

29. Hall LE, Chalfoun AD, Beever EA, Loosen AE. Microrefuges and the occurrence of thermal specialists: implications for wildlife persistence amidst changing temperatures. Climate Change Responses. 2016 Dec [cited 2016 Oct 20];3(1). Available from: http://climatechangeresponses.biomedcentral. com/articles/10.1186/s40665-016-0021-4

30. Huntley B, Webb TI. Migration: Species' response to climatic variations caused by changes in the Earth's orbit. J Biogeogr. 1989:16(1):5-19.

31. Parmesan C, Yohe G. A globally coherent fingerprint of climate change impacts across natural systems. Nature. 2003:421(6918):37-42.

32. Root T, Price J, Hall K, Schneider S, Rosenzweig C, Pounds J. Fingerprints of global warming on wild animals and plants. Nature. 2003;421(6918):57-60.

33. Keppel G, Niel Van PK, Wardell-Johnson GW, Yates CJ, Byrne M, et al. Refugia: identifying and understanding safe havens for biodiversity under climate change. Glob Ecol Biogeogr. 2011:21(4):393-404.

34. Ashcroft MB, French $\mathrm{KO}$, Chisholm LA. A simple post-hoc method to add spatial context to predictive species distribution models. Ecol Model. 2012 228:17-26.

35. Morelli TL, Daly C, Dobrowski SZ, Dulen DM, Ebersole JL, Jackson ST, et al. Managing climate change refugia for climate adaptation. PLoS One. 2016; 11(8):e0159909.

36. Stillman JH. Acclimation capacity underlies susceptibility to climate change. Science. 2003;301(5629):65-5.

37. Chown SL, Gaston KJ, Robinson D. Macrophysiology: large-scale patterns in physiological traits and their ecological implications. Funct Ecol. 2004;18(2): 159-67.

38. Chown SL, Slabber S, McGeoch MA, Janion C, Leinaas HP. Phenotypic plasticity mediates climate change responses among invasive and indigenous arthropods. Proc R Soc B. 2007;274(1625):2531-7.

39. Thuiller W, Richardson DM, Pyšek P, Midgley GF, Hughes GO, Rouget M. Niche-based modelling as a tool for predicting the risk of alien plant invasions at a global scale. Glob Chang Biol. 2005; 11(12):2234-50.

40. Thomas CD, Bodsworth EJ, Wilson RJ, Simmons AD, Davies ZG, Musche M, et al. Ecological and evolutionary processes at expanding range margins. Nature. 2001;411(6837):577-81.

41. Figueirido B, Janis CM, Pérez-Claros JA, De Renzi M, Palmqvist P. Cenozoic climate change influences mammalian evolutionary dynamics. Proc Natl Acad Sci. 2011:109:722-7.

42. Holt RD. The microevolutionary consequences of climate change. Trends Ecol Evol. 1990:5(9):311-5.

43. Parmesan C. Ecological and evolutionary responses to recent climate change. Annu Rev Ecol Evol Syst. 2006:37:637-69.

44. Thuiller W, Lavorel S, Araujo MB, Sykes MT, Prentice IC. Climate change threats to plant diversity in Europe. Proc Natl Acad Sci U S A. 2005:102(23): 8245-50. 
45. Pearson RG, Dawson TP. Predicting the impacts of climate change on the distribution of species: are bioclimate envelope models useful? Glob Ecol Biogeogr. 2003;12:361-71.

46. Walther G-R, Post E, Convey P, Menzel A, Parmesan C, Beebee RJC, et al. Ecological responses to recent climate change. Nature. 2002;416:38995.

47. Harter DEV, Ir| SDH, Seo B, Steinbauer MJ, Gillespie R, Triantis KA, et al. Impacts of global climate change on the floras of oceanic islands Projections, implications and current knowledge. Perspect Plant Ecol Evol Syst. 2015;17(2):160-83.

48. Maggini R, Lehmann A, Zbinden N, Zimmermann N, Bolliger J, Schroder B, et al. Assessing species vulnerability to climate and land use change: the case of the Swiss breeding birds. Divers Distrib. 2014;20:708-19.

49. Polsky C, Neff R, Yarnal B. Building comparable global change vulnerability assessments: The vulnerability scoping diagram. Glob Environ Chang. 2007; 17(3-4):472-85.

50. Chevin L-M, Lande R, Mace GM. Adaptation, plasticity, and extinction in a changing environment: towards a predictive theory. PLoS Biol. 2010;8(4): e1000357.

51. Davidson AM, Jennions $M$, Nicotra AB. Do invasive species show higher phenotypic plasticity than native species, and if so, is it adaptive? Meta Anal Ecol Lett. 2011;14(4):419-31.

52. Coops NC, Waring RH. Estimating the vulnerability of fifteen tree species under changing climate in Northwest North America. Ecol Model. 2011;222: 2119-29.

53. Trisurat $Y$, Shrestha RP, Kjelgren R. Plant species vulnerability to climate change in peninsular Thailand. Appl Geogr. 2011;31:1106-14.

54. Lloret F, Gonzalez-Mancebo JM. Altitudinal distribution patterns of bryophytes in the canary islands and vulnerability to climate change. FLORA. 2011;206:769-81.

55. Rowland EL, Davison JE, Graumlich LJ. Approaches to evaluating climate change impacts on species: a guide to initiating the adaptation planning process. Environ Manag. 2011;47(3):322-37.

56. Johnstone JF, Chapin FS. Non-equilibrium succession dynamics indicate continued northern migration of lodgepole pine. Glob Chang Biol. 2003;9: 1401-9.

57. Ashcroft MB. Identifying refugia from climate change. J Biogeogr. 2010;37(8): 1407-13.

58. Davis MB, Shaw RG. Range shifts and adaptive responses to quaternary climate change. Science. 2001;292(5517):673-9.

59. Nobis MP, Jaeger JAG, Zimmermann NE. Neophyte species richness at the landscape scale under urban sprawl and climate warming. Divers Distrib. 2009;15:928-39.

60. Clements DR, Ditommaso A. Climate change and weed adaptation: can evolution of invasive plants lead to greater range expansion than forecasted? Weed Res. 2011;51:227-40.

61. Alexander JM, Diez JM, Levine JM. Novel competitors shape species' responses to climate change. Nature. 2015;525:515-8.

62. Gilman SE, Urban MC, Tewksbury J, Gilchrist GW, Holt RD. A framework for community interactions under climate change. Trends Ecol Evol. 2010;25(6): 325-31.

63. Tylianakis JM, Didham RK, Bascompte J, Wardle DA. Global change and species interactions in terrestrial ecosystems. Ecol Lett. 2008;11(12): 1351-63.

64. Lenoir J, Gégout JC, Marquet PA, de Ruffray P, Brisse H. A significant upward shift in plant species optimum elevation during the 20th century. Science. 2008;320(5884):1768-71.

65. Perry AL, Low PJ, Ellis JR, Reynolds JD. Climate change and distribution shifts in marine fishes. Science. 2005;308:1912-5.

66. Baker AC, Starger CJ, McClanahan TR, Glynn PW. Coral reefs: Corals' adaptive response to climate change. Nature. 2004;430(7001):741-1.

67. Berteaux D, Réale D, McAdam AG, Boutin S. Keeping pace with fast climate change: Can arctic life count on evolution? Integr Comp Biol. 2004;44(2): 140-51.

68. Mackey B, Berry S, Hugh S, Ferrier S, Harwood TD, Williams KJ. Ecosystem greenspots: identifying potential drought, fire, and climate-change microrefuges. Ecol Appl. 2012;22(6):1852-64.
69. Maclean IMD, Hopkins JJ, Bennie J, Lawson CR, Wilson RJ. Microclimates buffer the responses of plant communities to climate change. Glob Ecol Biogeog. 2015;n/a-n/a.

70. Fortini LB, Price J, Jacobi JD, Vorsino AE, Burgett J, Brinck KW, et al. A landscape-based assessment of climate change vulnerability for all native Hawaiian plants. Hilo, HI, USA: Hawaii Cooperative Studies Unit; 2013 p. 141. Report No.: 44. Available from: http://hilo.hawaii.edu/hcsu/ documents/TR44_Fortini_plant_vulnerability_assessment.pdf

\section{Submit your next manuscript to BioMed Central and we will help you at every step:}

- We accept pre-submission inquiries

- Our selector tool helps you to find the most relevant journal

- We provide round the clock customer support

- Convenient online submission

- Thorough peer review

- Inclusion in PubMed and all major indexing services

- Maximum visibility for your research

Submit your manuscript at www.biomedcentral.com/submit 